\title{
Término de un periodo editorial, 2004-2016
}

La Revista Chilena de Obstetricia y Ginecología nace junto con la fundación de la Sociedad Chilena de Obstetricia y Ginecología en octubre de 1935, siendo la tercera más antigua después de la Revista Médica de Chile (1872) y de Pediatría (1930). Tanto la Sociedad como la Revista surgen de la necesidad de los ginecólogos y obstetras de compartir las experiencias de sus Servicios, con fines de ofrecer la mejor medicina que se podía otorgar a la mujer en esos momentos, en que los tratamientos estaban basados en la experiencia y no en la evidencia, como es en la actualidad. Eran épocas en que el cáncer ginecológico y la muerte materna eran una de las principales causas de mortalidad de la mujer joven y no se disponía más que de la enorme pericia de nuestros antiguos maestros en el arte quirúrgico y obstétrico. Esas experiencias están publicadas y a disposición en la Biblioteca de la Sociedad para que los gineco-obstetras en formación aprecien como ha cambiado la epidemiología de las patologías gineco-obstétricas y la forma de abordarlas, con los escasos o ningún método diagnóstico que se disponía en esos momentos. Han pasado 81 años desde el primer número de la Revista que se llamó inicialmente Boletín de la Sociedad Chilena de Obstetricia y Ginecología y se ha publicado ininterrumpidamente desde esa fecha. Tuvimos presencia en Index Medicus/MEDLINE desde 1950 hasta 1995, lamentablemente la perdimos por la pérdida de la contemporaneidad de la publicación de los números y es un desafío no cumplido de reinsertarnos en esa plataforma. Mi primer contacto con la Revista fue en mis inicios como alumno de posgrado de la especialidad en 1973, donde se presentaban en sesión plenaria los trabajos que posteriormente se publicarían. Era fascinante oír discutir a los maestros contrastando sus experiencias que constituían normas en sus Servicios, esto me estimuló a ingresar como socio activo de la Sociedad en 1975 con el trabajo "El significado del estriol en líquido amniótico" (Donoso y cols 1975;40:220-7), y desde esa fecha he mantenido una permanente y entrañable relación con la Sociedad y la Revista. Fue así que en 2004, el maestro chileno y latinoamericano de la Obstetricia y Ginecología Dr. Mario Herrera Moore, renuncia al cargo de Editor Jefe (1989-2003) y me recomienda para ejercer esa labor, lo que fue refrendado por el Presidente de la Sociedad Chilena de Obstetricia y Ginecología Dr. Enrique Oyarzún Ebensperger (2004-2005). El cargo de Editor Jefe lo he ejercido desde 2004 hasta diciembre de 2016. Han sido 12 años de arduo trabajo, pero he estimado necesario una renovación del cargo y dar un paso al lado para permitir que nuestra Revista continúe creciendo, se profesionalice su gestión editorial para lograr reinsertarnos nuevamente en Index Medicus/MEDLINE. En esos 12 años han pasado muchas cosas, quizás la más importante es que por razones de financiamiento la Revista dejó de publicarse en formato papel en diciembre de 2008, pasando desde entonces solo a difusión on-line en la plataforma Scielo (www.scielo. cl) y en el sitio web de la Sociedad Chilena de Obstetricia y Ginecología (www.revistasochog. cl) con acceso abierto a la comunidad médica nacional e internacional, con los parámetros de calidad formal de una publicación electrónica, establecidos por el sistema Latindex para revistas en ese formato, y exigidas por la plataforma SciELO para este tipo de publicaciones. Estar en internet permitió a nuestro órgano de difusión salir del enclaustramiento nacional y se internacionalizó. Es así que antes de estar en la web las contribuciones eran exclusivamente de médicos chilenos, en la actualidad, a modo de ejemplo, en los seis números de 2016 disponemos de 22 contribuciones de España, 19 de Colombia, 18 de Chile, 5 de Perú, 2 de México, 2 de Venezuela, 1 de Argentina y 1 de Cuba, quienes han visto en nuestra Revista una buena plataforma para compartir sus experiencias y hemos pasado a ser prácticamente una Revista Hispanoamericana de Obstetricia y Ginecología. El nuevo Editor Jefe a partir del №1 de 2017 será el Dr. Mauricio Cuello Fredes, médico gineco-obstetra especialista en Oncología Ginecológica, past Presidente de la Sociedad Chilena de Obstetricia 
y Ginecología (2014-2015) y actual Director de Investigación de la Escuela de Medicina de la Pontificia Universidad Católica de Chile, quién sin duda con su gran capacidad de gestión y trabajador infatigable, logrará posesionar a nuestra revista en el sitial que se merece. A modo de despedida del cargo de Editor Jefe, deseo compartir con ustedes, y muy especialmente con mis colegas extranjeros, el manuscrito "El aborto en Chile: aspectos epidemiológicos, históricos y legales" que les permitirá conocer como Chile ha enfrentado este cruel flagelo, principal causa de muerte materna en muchos países latinoamericanos.

Dr. Enrique Donoso Siña.

Editor Jefe.

Revista Chilena de Obstetricia y Ginecología. (2004-2016). 